\title{
ENSINO DE LITERATURA E LIVRO DIDÁTICO: UMA ABORDAGEM A PARTIR DAS PESQUISAS NA PÓS-GRADUAÇÃO BRASILEIRA
}

\author{
TEACHING OF LITERATURE AND THE TEXTBOOK: AN APPROACH DERIVED FROM RESEARCH \\ ON BRAZI LIAN POSTGRADUATE COURSES
}

Danielle Amanda Raimundo Silva

Mestranda em Estudos da Tradução pela UFSC.

Celdon Fritzen

Doutorado em Teoria e História Literária pela UNICAMP.

Centro de Comunicação e Expressão Universidade Federal de Santa Catarina (UFSC)

Florianópolis - SC - Brasi

Endereço:

Rua Padre Cícero, 167

Centro - Criciúma - SC

CEP: $88802-150$

Rua 14 de julho, 133 - Bloco 204 E

Estreito - Florianópolis - SC

CEP: 88075-010

E-mails:

daniellefleur@gmail.com

celdon@hotmail.com

RESUMO

Com o intuito de melhor compreender a realidade do ensino de literatura no Brasil a partir da produção de conhecimento dos seus programas de pós-graduação, desenvolvemos a pesquisa Uma análise do Banco de teses e dissertações da CAPES sobre o Ensino de Literatura. A partir das ponderações de um corpus com 107 resumos, discutimos a problemática relação que se estabelece entre ensino de literatura e livro didático e, diante disso, qual a postura já assumida pelo professor em sala de aula, bem como o papel desejável a ser assumido por esse profissional que traz consigo, conforme as suas atitudes, a possibilidade de fazer da atividade de leitura algo pragmático ou um meio à fruição estética. A análise das pesquisas aponta para a importância do trabalho com textos autênticos - o que se constitui em um modo de fugir das concepções redutoras de texto e de leitura não raramente encontradas no livro didático as quais acabariam por eliminar o prazer estético. Faz-se, portanto, o apelo para que o livro didático seja apenas um instrumento de apoio ao trabalho docente e não um parâmetro às aulas.

PALAVRAS-CHAVE: Ensino de Literatura. Livro Didático. Mediação Pedagógica.

ABSTRACT

In an attempt to better understand the reality of Literature teaching in Brazil, based on the production of knowledge of its postgraduate programs, we developed the research An analysis of the CAPES thesis and 
dissertations bank on Literature Teaching. Based on a corpus of 107 abstracts, we discuss the problematic relationship that is established between the teaching of Literature and textbook and, based on it, the stance already taken by teachers in the classroom, as well as the desirable role to be assumed by this same professional who brings with him/himself, according to her/his attitudes, the possibility of turning the activity of reading into something pragmatic, or a means to aesthetic enjoyment. Analysis of the postgraduate studies indicates the importance of working with authentic texts - which constitutes a way of escaping from the reductive reading concept of text frequently found in textbooks, which eliminates aesthetic pleasure. Thus, an appeal is made for textbooks to be used merely as a tool to support teaching, and not a parameter for classes.

KEYWORDS: Literature Teaching. Textbook. Pedagogical Mediation.

INTRODUÇÃO

A fim de melhor compreender os desdobramentos pelo quais o ensino de literatura passa em nosso País, propôs-se a pesquisa Uma análise do Banco de teses e dissertações da CAPES (BTDC) sobre o Ensino de Literatura. Seu objetivo era entender os motivos do fracasso ou sucesso da disciplina literatura, segundo as pesquisas de pós-graduação. Com base nas ponderações feitas dentre um corpus final de 107 resumos, correspondentes a teses e dissertações defendidas entre 1988 e 2006, neste artigo, problematizaremos o importante papel a ser desenvolvido pelo professor como mediador da leitura, frente à problemática relação que se estabelece entre ensino de literatura e o livro didático no Brasil. Antes, porém, de tratar diretamente sobre o papel do professor de língua portuguesa/literatura, discutiremos a relação entre ensino de literatura e o papel do livro didático nesse ensino, tomando como base aquilo que é exposto nas pesquisas de pós-graduação analisadas ${ }^{1}$. Para isso organizamos este artigo em dois grandes blocos: o primeiro problematiza a presença do texto literário como pretexto para outros fins que não o da experiência estética; o segundo aborda o uso do livro didático e a mediação do professor no papel de formação de leitores literários.

\section{ENSINO DE LITERATURA E O LIVRO DIDÁTICO}

Subsidiado pelo Governo Federal desde meados de 1930 - haja vista a criação do Instituto Nacional do Livro Didático (INL), em 1929 - e intimamente ligado a diversas políticas públicas até a atualidade, historicamente, o que se constata é a adoção do livro didático com o intuito de amenizar "as desigualdades criadas por um sistema econômico e social injusto, com enormes discrepâncias sócio-econômicas entre ricos e pobres" (FREITAG, et al.: 19).

No entanto, ainda que políticas governamentais cuidassem da compra e da distribuição de livros didáticos aos alunos carentes, nem sempre a qualidade de conteúdo desse material foi posta em discussão. Nos idos de 1988, por exemplo, devido à falta de metodologia na escolha daquilo que deveria ser lido por alunos de uma ou outra faixa etária, segundo pesquisa feita por Molina, "surgiram vários casos (dezessete) em que um mesmo texto foi selecionado para livros destinados a séries distintas" (1988: 49), o que faz pensar sobre os critérios imprecisos que presidiriam a seleção.

Esse trabalho de avaliação qualitativa dos livros didáticos, negligenciado pelo Estado, começou a ser desempenhado pelos programas de pós-graduação brasileira só a partir da década de 80 , constituindo, assim, valiosos estudos críticos desse material, chamando "a atenção dos técnicos, assessores e burocratas" (FREITAG et al., 1997: 23-4). Os estudos que compõem o corpus da pesquisa Uma análise do Banco de teses e dissertações da CAPES sobre o Ensino de Literatura, distribuídos entre os anos de 1988 e 2006, demonstram que o espaço de crítica e discussão aberto na década de 80 cresce com passar dos anos.

Dada a contribuição oferecida pelas pesquisas de pós-graduação, essas serão aqui apresentadas e comentadas no intuito de abordar a relação que se estabelece entre o ensino de literatura e o livro didático nas escolas brasileiras em contexto de Ensino Fundamental e Médio. Primeiramente, no que diz respeito às adaptações que os textos literários sofrem quando adentram no espaço do livro-texto: sua acomodação a interesses didáticos geraria consequências na forma como são percebidos e lidos. 
Ponto recorrente em dezesseis pesquisas que tiveram sua realização distribuída por oito estados (MS; PR; PE; SP; MG; RJ ; PB e SC), a didatização do texto literário se constitui como um fenômeno que já era sentido e denunciado por Lajolo (1982: 29):

\begin{abstract}
(...) algumas editoras, tentando ampliar a faixa de mercado de autores contemporâneos, acompanham seus livros de instruções de uso, ou seja, de fichas, roteiros e questões que sugerem ao professor os caminhos de penetração na obra. Desnecessário dizer-se que, nesta adaptação escolar, qualquer vanguarda perde seu vanguardismo, obrigada a moldar-se aos clichês literários já sancionados pela escola.
\end{abstract}

De tal forma que esses processos de adaptação da literatura a leituras estreitamente direcionadas em detrimento da experiência estética faz com que sua apropriação pelo livro didático seja objeto de críticas veementes:

O livro didático concebe o ensino de literatura apoiado no tripé conceito de leitura-texto-exercício [...] o conceito de leitura e de literatura que a escola adota é de natureza pragmática, aquele só se justifica quando explicita uma finalidade - a de ser aplicado, investido, num efeito qualquer. (ZILBERMAN, 1988: 111).

Logo, o texto literário é abordado pelos livros didáticos de tal forma que acaba por dissociá-lo de sua qualidade artística, não pragmática. Atribuindo-lhe uma função imediata, um texto literário transforma-se em mero texto didático, pois “quando passamos o estilo de um gênero para outro, não nos limitamos a modificar a ressonância deste estilo graças à sua inserção num gênero que não Ihe é próprio, destruímos e renovamos o próprio gênero" (BAKHTIN, 2000: 286).

Portanto, se concordarmos com a abordagem trazida pelo livro didático que sugere uma leitura a fim de que a realização de um exercício seja possível, teremos em mãos um texto escolar; no entanto, se ignorarmos a atividade sugerida e simplesmente lermos o texto trazido pelo compêndio, teremos novamente um texto literário. Assim sendo, "a definição de literatura fica dependendo da maneira pela qual alguém resolve ler, e não da natureza daquilo que é lido" (EAGLETON, 1997: 11).

Em relação a isso, Zilberman lembra que o texto é "intermediário entre o sujeito e o mundo [...] ler passa a significar igualmente viver a realidade por intermédio do modelo de mundo transcrito no texto" (1988: 18). Contudo, se o exercício de leitura surge com vistas a um fim previsto, não poderá o aluno usufruir do texto como fonte de conhecimento daquilo que até então lhe era alheio ou, mesmo, como um dispositivo capaz de despertar a imaginação, o prazer estético.

A autora da dissertação Prática e leitura de textos literários no Ensino Fundamental denuncia, justamente, a abordagem pragmática da obra literária, ao concluir que o estudo proposto pelos livros didáticos "se pauta por um modelo de análise imanentista, que trata o texto como objeto a ser analisado no seu aspecto linguístico e estrutural" (ASSUNÇÃO, 1998). Sem exigir do leitor capacidade de interpretação, mas tão somente de decodificação do código escrito, tal abordagem, ainda segundo a autora, fere os princípios da estética da recepção, os quais concebem o ato de ler como um processo de interação texto/ leitor.

Já, em sua tese de doutorado, ao fazer um estudo sobre a importância da literatura infantil no processo histórico de formação da infância até os dias atuais, Oliveira (2001) chama à atenção para o fato de que a literatura infantil,

\footnotetext{
(...) sendo um gênero literário presente na escola tem muito a contribuir para desenvolver a sensibilidade estética do leitor e ainda propiciar conhecimentos, por conta de um envolvimento intenso e prazeroso da criança com o livro escolhido, sem atrelamento ao ensino moralizante, como ainda é concebido na prática escolar.
}

A escola tende a privilegiar a leitura capaz de inspirar certas condutas, coisa que ocorre quando indica para leitura obras cujo enredo possa ser usado como pretexto para debates. Desse modo, a escola relega ao exercício de leitura uma finalidade moral, fugindo à propriedade "não pragmática" da literatura; em outras palavras: ao converter o texto literário em instrumento pedagógico de outra disciplina ou saber, estar-se-ia subordinando a arte à pedagogia. Vale ponderar que o objeto estético é um dispositivo capaz de provocar reflexão e múltiplas leituras, enquanto a mensagem que o leitor poderá depreender de uma dessas obras correntemente lidas em âmbito escolar seria uma mensagem relativamente simples, como por exemplo: "não use drogas" - o que não necessariamente demandaria as horas de leitura que o aluno passa tentando assimilar um ensinamento que talvez ele já saiba. 
Para que a Literatura aconteça, o leitor é tão decisivo quanto o escritor. Se em sala de aula o texto literário não é concebido como expressão cultural carregada de significados, pouco se estará atento ao papel fundamental daquele a quem deveria ser dada a oportunidade de usufruir o texto. Reflexo desta preocupação, a tese Letramento literário na escola descreve e analisa como ocorre o processo de formação do jovem (pré-adolescente) como leitor de literatura, por meio de suas práticas de leitura em livros didáticos e em outros suportes impressos usados em sala de aula. A autora pôde observar que, na escola pública brasileira investigada,

(...) o leitor que se pretende formar deve ler o que é permitido, seguindo os valores transmitidos por essa importante formadora da 'comunidade de leitores'. Esses valores são veiculados, principalmente, através do livro didático, que costuma guiar as práticas de leitura realizadas na sala de aula. (PINHEIRO, 2006).

A autora observou também que o objetivo estético mistura-se a um objetivo instrucional. Além disso, as práticas de leitura realizadas em âmbito escolar acabam por influenciar as leituras fora da sala de aula. Outro fator determinante esbarra nas possibilidades de acesso a livros: "a biblioteca da escola constitui-se em um espaço que propicia e controla leituras", concluiu.

Não menos sofríveis parecem ser as abordagens propagadas pelo livro didático. Conforme aponta a tese de Padilha, o texto poético não é compreendido como objeto estético. Segundo conclusões da autora, mediante análise de quatro coleções de $1^{a \mathfrak{a}}$ a $4^{\underline{a}}$ séries e três coleções de $5^{\underline{a}}$ a 8a séries, estas:

(...) não favorecem a formação do leitor literário no ensino fundamental, pois não tomam os gêneros poéticos como objetos de ensino, não os usam nas atividades de leitura e privilegiam apenas seus aspectos formais ou a subjetividade do aluno-leitor. (PADILHA, 2005).

Não só no ensino fundamental se faz necessário chamar atenção para a natureza específica do texto literário. A esse respeito discrepâncias entre o ideal e o real foram discutidas pelas pesquisas do BTDC também em contexto de ensino médio. Vale lembrar que a função não pragmática do texto literário foi registrada nas Orientações Curriculares para o Ensino Médio (2006: 49). A chamada de consciência para tal especificidade se constitui em um progresso, haja vista que se faz presente em documentos oficiais, ou seja, vai além do espaço de crítica e reflexão dos programas de pósgraduação. Ainda assim, as abordagens encontradas pelas pesquisas sobre o ensino de literatura no BTDC em muito deixam claro o distanciamento da prática existente nas escolas daquela que compreenderia o texto literário como instrumento para a formação crítica e estética de leitores.

Com o intuito de observar qual a importância da Literatura na formação do aluno de escola pública e de que maneira estão sendo ministrados os conteúdos curriculares dessa disciplina no Ensino Médio, a dissertação de Santos (2005) observou a prática de quatro professores em sala de aula em uma escola da cidade de Campo Grande, MS. A partir daí, o autor estudou como se dá a concretização estética das significações da leitura literária e da formação do aluno-leitor, sem deixar de considerar as intenções, as opiniões e os traços sociais que valoram a arte literária. Segundo o autor,

[...] a procura, a busca pelo inusitado, a cumplicidade que se instaura entre autor e leitor durante o ato da leitura não se concretizou durante as aulas observadas. O mais importante para os professores observados era que o aluno apreendesse a História da Literatura Brasileira e interpretasse suficientemente um texto literário, traduzindo essa interpretação como análises lógicas e gramaticais da palavra do poeta. (SANTOS, 2005).

O que podemos depreender de tais constatações é que, em ambiente escolar, dissocia-se literatura de língua e arte. A lista de características, autores e obras representativas das escolas literárias se constitui em conteúdo que deverá ser repassado e memorizado, ano após ano, pelos alunos a quem resta apenas absorver passivamente o que lhes é transmitido. As sistematizações do ensino de literatura, ainda hoje presentes nas escolas, constituem uma prática cristalizada que se mantém e na qual os livros didáticos frequentemente estão ancorados. Ora, se os textos provenientes de épocas anteriores forem estudados sem que se mostre sua importância como diálogo com um determinado momento histórico no qual o pensamento humano o produziu, de muito pouco valerá tal leitura para a construção do sujeito que se descobre membro de uma sociedade e que dela tende a herdar ou deslegitimar valores culturais construídos através dos tempos: "A cultura é uma continuidade em transformação. Não pode existir nem no vácuo da tradição nem na imobilidade e 
no isolamento. Nossa tradição não é 'a continuidade mística da substância cultural ocidental', mas a memória cumulativa de um processo histórico" (PERRONE-MOISÉS, 1998: 202).

Embora possa configurar-se em instrumento de desenvolvimento das competências humanísticas e, por isso, em se tratando de ensino formal, valioso desde o ensino fundamental, para a grande maioria dos alunos o contato com obras literárias dá-se apenas no ensino médio. A rejeição ao diferente, àquilo que provoca estranhamento tende, pois, a surgir. Em uma tentativa de resolver o problema, mas o tornando de proporções ainda maiores, o livro didático geralmente traz resumos de obras literárias. A dissertação A trama do texto no livro didático, defendida há pouco mais de 16 anos, já denunciava tal prática:

(...) a leitura direcionada pela obra didática de língua e de literatura não se limita apenas a restringir as possibilidades de leitura que o aluno de segundo grau teria diante de uma obra literária. Pior que determinar qual o entendimento que se deve ter da obra literária, a obra didática prevê que o aluno sequer a irá ler. (DINIZ, 1994).

Também as ponderações feitas pela dissertação A leitura, o ensino de literatura e o livro didático: uma questão a ser discutida resumem o apelo comum deixado pelos estudos que se deparam com o processo de didatização da literatura pelo livro didático: que este material não se apresente como o detentor do saber legítimo, não privilegie a abordagem histórico-informativa do texto literário, a fim de que se possa desenvolver no aluno o gosto pela leitura e o seu despertar crítico (VIOTTO, 2004).

Apontados como entraves à efetivação do ensino de literatura, os problemas de letramento são explicitados apenas por pesquisas que ocorreram no contexto de Ensino Médio - provável consequência das lacunas deixadas durante o Ensino Fundamental. Seja pelo despreparo docente ou pela má qualidade do livro didático, quatro pesquisas, realizadas em SP, PE e PR, entre os anos de 1998 e 2005, versam acerca dessa temática.

Há pouco tempo, as denominações analfabetizado e alfabetizado bastavam para descrever o nível de domínio das habilidades de leitura e escritura. No entanto, na atualidade, não basta mais saber ler e escrever, decodificar e codificar: é preciso também estar apto a usufruir daquilo que a leitura e a escrita podem proporcionar, porque as possibilidades de interação em sociedade tendem a ser maiores na mesma proporção que o nível de letramento for mais apurado.

Com vistas à relação de alunos do Ensino Médio para com a leitura, estudo realizado por Dante (2006), em sua dissertação, reflete o quadro de consciência dos estudiosos acerca do problema:

\footnotetext{
É reafirmada a responsabilidade da escola em promover diferentes letramentos utilizando variados objetos de leitura, o que possibilitaria o desenvolvimento de capacidades específicas. Essa responsabilidade abrange necessariamente o letramento literário que, por estar sendo negligenciado ou descaracterizado, demanda inovações pedagógicas urgentes.
}

Quando um aluno passa todo seu ensino fundamental sem ter a oportunidade de construir, ao longo de seu desenvolvimento cognitivo, um acervo de leituras que proporcione refinamento de sua sensibilidade estética, é natural que este mesmo aluno não goste de ler e tenha dificuldade de construção de texto, em especial do literário. Assim, alunos que tiveram uma apropriação deficiente das práticas de leitura, apresentarão dificuldades, como ocorrido aos candidatos da prova de Literatura e Língua Portuguesa do vestibular da Universidade Estadual de Campinas - UNICAMP. Nesse caso, em específico, problemas de leitura foram constatados: "não só em relação ao texto da obra literária, mas também em relação ao enunciado da questão do vestibular. Os alunos indicam alguns problemas básicos de letramento, como insuficiência de vocabulário e falta de habilidade para redigir uma resposta clara e concisa", conclui Ferreira (1998) em sua dissertação. Em termos gerais, tais problemas nada mais são do que o reflexo de um ensino de leitura que há muito é carente.

\section{O PROFESSOR DIANTE DA RELAÇÃO LIVRO DIDÁTICO E ENSINO DE LITERATURA}

Ainda que na atualidade políticas de incentivo à leitura tenham se popularizado, como o Programa Nacional da Biblioteca da Escola (PNBE), do Ministério da Educação; e o Programa Nacional de Incentivo à Leitura (Proler), do Ministério da Cultura, tais medidas "não modificam a aposta antiga de que a escola constitui o espaço preferencial de desenvolvimento da capacidade de leitura e que seu principal agente é o professor" (LAJOLO \& ZILBERMAN, 2009b: 125). A discussão que levantamos 
agora, com base nos apontamentos feitos pelas pesquisas do BTDC, dirige-se tanto à postura real do professor quanto àquela que seria a desejável para que mudanças acontecessem no ensino de literatura. Diga-se que a crítica à prática docente aparece em um total de treze proposições, passando por várias regiões brasileiras (RS; PR; DF; PI; SP; RJ; PB; MT).

Atualmente, a opção do professor recai sobre uma seleção elaborada por comissão do Fundo Nacional de Desenvolvimento da Educação (FNDE), porém, visto que somente desde 1996 é feita a avaliação pedagógica sistemática do material didático, foram muitos os anos nos quais as escolhas do professor eram diretamente influenciadas pela propaganda editorial.

Em 1988, Molina relatava:

(...) quem edita mais divulga mais e, com isso, forma-se um círculo vicioso: as editoras mais poderosas exercem maior pressão sobre os professores (pela distribuição de exemplares gratuitos e pela propaganda maciça) e, sendo mais conhecidas, têm suas obras entre as mais escolhidas. [...] De pouco adianta poder escolher quando não se sabe escolher. (p.24).

Os professores, à época, não saberiam escolher, pois era vista a precariedade de sua formação. Com o aumento da escolaridade mínima de cinco para oito anos (instituída no início da década de 70), a fim de suprir a demanda por mais professores, deu-se o que Zilberman chama de "proliferação das licenciaturas", assunto sobre o qual argumenta: "A formação apressada do professor não poderia esconder seu despreparo [...] A solução foi trocar o docente por engrenagens que atuassem em seu lugar [...]" (1988: 74). Assim sendo, a não criticidade docente abriu margem ao uso do livro didático para além de um instrumento, transformando-o em parâmetro às aulas. Fato este que implica a aceitação passiva das abordagens do texto literário nele contidas.

Por parte dos professores, somada a não criticidade em relação ao livro didático, estaria sua estagnação diante do atual modelo de ensino literário. Isso pode ser exemplificado por uma pesquisa de mestrado realizada na Paraíba, que investigou o trabalho com a literatura no 1 o ano do Ensino Médio nas escolas públicas e particulares, nela o autor percebeu que, por parte dos professores, não há uma preocupação com os adolescentes no sentido de oferecer-lhes um ensino de literatura voltado para seus interesses literários. Por sua vez, os docentes se mostram preocupados com o desapego dos alunos diante dos textos, o que eles atribuem à falta do hábito da leitura literária. Apesar disso, modificações na prática docente com vistas a uma mudança nos parâmetros de seleção daquilo que deve ser lido não são cogitadas. "Ainda que sigam as orientações dos livros didáticos, os professores tecem inúmeras críticas tanto aos textos presentes nestes livros quanto às suas abordagens" (CORDEIRO, 2002), o que supõe que esses professores não têm autonomia suficiente para buscar textos e novas abordagens além daquelas que se encontram no livro didático.

A dissertação A leitura literária nas $3^{\underline{a}}$ e 4ạ séries do Ensino Fundamental do município de Londrina analisa como foi conduzido o trabalho com Literatura pela Rede Municipal dessa cidade desde a década de 60. Suas conclusões apontam para “um processo de didatização da leitura, evidenciando o desconhecimento teórico dos informantes sobre a natureza específica do texto literário, sobre seu conteúdo e metodologia" (SILVA, 2001). A falta de metodologia na atuação docente, o desconhecimento do acervo literário com o qual poderiam melhor desenvolver suas aulas, por vezes agravada pela precariedade de recursos da escola pública, configuram-se nas críticas mais comuns. Além disso, há o reconhecimento por parte dos pesquisadores da má formação dos docentes e mesmo de sua incapacidade para buscar interação entre o aluno-leitor e o texto.

O estudo Retratos da leitura no Brasil (2007), divulgado pela Imprensa Oficial do Estado de São Paulo, aponta:

O papel da escola na formação de leitores deve ir além do domínio da leitura e do acesso ao livro. Os vários suportes e os diferentes códigos e mídias devem ser tratados no ambiente escolar, na perspectiva de democratização do acesso aos diversos bens culturais e sociais disponíveis na sociedade contemporânea. A política deve focalizar na formação do comportamento leitor, facilitado pela viabilização de livros cada vez mais acessíveis para todos os brasileiros, e práticas pedagógicas que promovam a produção e a leitura, a exemplo das oficinas de professores e alunos para a produção de textos, [...]. (AMORIM, 2008: 78).

Desenvolver a percepção crítica do docente acerca de seu papel fundamental na mediação aluno-texto, cuidando em ser leitor ativo e em constante formação ele próprio; trabalhando, na medida do possível, sem fragmentar os textos como costuma fazer o livro didático - caracterizam-se 
como passos a serem seguidos, de acordo com as pesquisas do BTDC, na inversão dos quadros de precariedade das habilidades de leitura dos jovens brasileiros que frequentam as escolas.

Para que tais objetivos tornem-se realidade, um encaminhamento possível seria o mesmo em vinte e uma pesquisas cuja realização passou pelos estados de SP, RJ, PE, RN, PI, PR e RS. Tratase, pois dá ênfase para a importância do contato do aluno com o texto literário, preferencialmente, integral. Em busca de meios que levassem as aulas de literatura a acontecerem desse modo, o professor estaria mais perto de desempenhar o papel de mediação entre alunos e leitura com vistas à formação de leitores.

A formação do sujeito leitor é um processo continuo, por isso, é possível supor que, quanto mais chances de contato entre os sujeitos e os textos literários forem proporcionadas, maiores serão as possibilidades de interação, mediadas pela leitura, desses sujeitos com o mundo no qual estão inseridos. A partir daí, abrir-se-ia margem para um gradativo aperfeiçoamento das competências de leitura e, até mesmo, de escritura de textos.

Muito embora os Parâmetros Curriculares Nacionais de Língua Portuguesa (1996) orientem para que no ensino fundamental o texto seja a base dos estudos, essa prática vem sendo não raramente negligenciada. Como instrumento no processo ensino-aprendizagem, Leahy-Dios sugere para o ensino de literatura uma "reestruturação curricular, de forma a incluir a produção literária mais recente, além da adoção de estratégias mais interativas nas salas de aula" (2004: 27). Tal reestruturação faz-se necessária ao passo que as lacunas existentes no ensino de literatura brasileiro verificam-se na forma essencialmente positivista de transmissão do conhecimento em detrimento da própria leitura da obra a ser estudada. Segundo a autora da dissertação A apresentação nos livros didáticos do Ensino Médio, "dessa forma, afastamos do aprendiz o prazer pela leitura dos clássicos e deixamos de apresentar as publicações contemporâneas pós-modernas, isto é, perdemos mais uma vez a oportunidade de motivar adequadamente o aluno" (JACONI, 2006).

Além de considerar a produção literária mais recente, tal qual apontado por Silva \& Fritzen (2009), o trabalho com o gênero poético se constitui uma possibilidade real para um ensino de literatura que, além de proporcionar deleite estético, colaboraria significativamente para a formação de sujeitos mais reflexivos e autônomos, estejam eles no ensino fundamental, médio, educação de jovens e adultos ou mesmo em contextos extraclasse.

A leitura do literário no âmbito escolar traz em sua base uma possibilidade ímpar: a de estabelecer uma ponte entre o individual e a coletividade, formando não apenas leitores, mas, também, comunidades de leitores. A esse respeito, comungamos da noção exposta por Colomer (2009: 144) e entendemos que:

Para a escola, as atividades de compartilhar são as que melhor respondem a esse antigo objetivo de "formar o gosto" a que aludimos; porque comparar a leitura individual com a realizada por outros é o instrumento por excelência para construir o itinerário entre a recepção individual das obras e sua valorização social.

Logo, a mediação que se espera operada entre texto e aluno por intermédio do professor, sendo ele leitor e crítico primeiro da obra a ser abordada, encontra nova e profícua possibilidade de desenvolvimento: a experiência de leitura pode ser compartilhada e construída socialmente.

Nesse ponto, é interessante ressaltar que o que aqui chamamos de experiência pode também corresponder, em alguns casos, a uma vivência. Anteriormente já citada, a tese de Padilha (2005) problematiza o livro didático como mero suporte que fica à mercê daquilo que se fará com os textos, ou fragmentos, que traz em si. Assim sendo, somente uma atividade sugerida pelo professor poderia garantir que uma cantiga de roda trazida pelo compêndio escolar seja mediada de modo a proporcionar uma vivência própria do gênero cantiga, por exemplo.

Contudo a permanência de abordagens empobrecedoras do texto literário por parte do livro didático encontraria sua justificativa na finalidade dada aos exercícios, cuja resposta deve estar acessível de um mesmo modo a todos os alunos (MOLINA, 1988: 111). Fora isso, o prazer estético advindo da leitura de um clássico, como nos lembra Cosson, dá-se pela "experiência estética que ele proporciona e não simplesmente pela história que conta" (2006: 63), não podendo, assim, ser substituída por nenhum outro dispositivo. 
O que se espera, afinal, é que os professores, seguramente também formados pelos livros didáticos em algum momento de sua escolarização, sejam usuários profissionais desse instrumento, já que não é possível negar o fato de que:

\begin{abstract}
O livro didático interessa igualmente a uma história da leitura porque ele, talvez mais ostensivamente que outras formas escritas, forma o leitor. Pode não ser tão sedutor quanto as publicações destinadas à infância (livros e histórias em quadrinhos), mas sua influência é inevitável, sendo encontrado em todas as etapas da escolarização de um indivíduo: é cartilha, quando da alfabetização; seleta, quando da aprendizagem da tradição literária; manual, quando do conhecimento das ciências ou da profissionalização adulta, na universidade. (LAJOLO \& ZILBERMAN, 2009a: 121).
\end{abstract}

\title{
CONSIDERAÇÕES FINAIS
}

Mesmo aqueles que têm acesso à escola, segundo pesquisas do BTDC, não necessariamente serão formados leitores, dado este que é confirmado pela pesquisa Retratos da leitura no Brasil (2007) do Instituto Pró-livro, quando denuncia que "a escola não está formando o leitor, mas dando acesso à leitura" (AMORIM, 2008: 74). Alvo de críticas por parte de todas as pesquisas que o tomam por objeto de discussão, em linhas gerais, o livro didático apresenta concepções de texto e de leitura que acabam por eliminar o prazer estético, situação agravada ainda quando deixa de ser um dos instrumentos de apoio à prática docente para ser, por vezes, o único.

Embora o trabalho com os textos autênticos seja requerido pelos estudiosos, nem o livro didático, nem os professores parecem solícitos ao aprimoramento de metodologias. Contudo a necessidade de um trabalho mais efetivo em contexto de ensino fundamental é um apelo que toma visibilidade a partir da dificuldade de se formar um leitor quando este já se encontra no ensino médio.

Entendemos, portanto, ser latente a necessidade de promoção de uma educação estética do sujeito que se pretende formar professor de literatura, visto que, muito provavelmente, foi ele mesmo vítima de um ensino que não concebia o texto literário como experiência estética - concepção que tende a reproduzir caso não a tenha desconstruída. Nesse aspecto, acreditamos que os resultados das pesquisas que aqui abordamos devam gerar subsídios de maneira a rever a formação literária do graduando de Letras, o futuro docente, como também para contribuir nas ofertas de formação continuada para professores que trabalham com a leitura, especificamente a literária.

REFERENCIAS

AMORIM, G.. (org.). Retratos da leitura no Brasil. São Paulo: Imprensa Oficial: Instituto Pró-livro, 2008.

BAKHTIN, M.. Estética da criação verbal. São Paulo: Ed. Martins Fontes, 2000.

COLOMER, T.. Andar entre livros: A leitura literária na escola. São Paulo: Global, 2009.

COSSON, R.. Letramento literário: teoria e prática. São Paulo: Contexto, 2006.

EAGLETON, T.. Teoria da literatura. 3. ed. São Paulo: Ed. Martins Fontes, 1997.

LAJ OLO, M.. Usos e abusos da literatura na escola: Bilac e a literatura escolar na república velha. Rio de J aneiro: Ed. Globo, 1982.

LAJ OLO, M. . \& ZILBERMAN, R.. A formação da leitura no Brasil. 3ạed. São Paulo: Ática, 2009a.

LAJ OLO, M.. \& ZILBERMAN, R.. Das tábuas da lei à tela do computador: a leitura em seus discursos. São Paulo: Ática, 2009b.

LEAHY-DIOS, C.. Educação literária como metáfora social: desvios e rumos. São Paulo: Martins Fontes, 2004.

LI NGUAGENS, códigos e suas tecnológicas. Brasília: Ministério da Educação Básica, 2006. (Orientações curriculares para o Ensino Médio, v.1) 
MOLINA, O.. Quem engana quem? Professor x livro didático. 2. ed Campinas, SP: Ed. Papirus, 1988.

PERRONE-MOISÉS, L.. Altas literaturas: escolha e valor na obra crítica de escritores modernos. São Paulo: Companhia das Letras, 1998.

SILVA, D. A. R. \& FRITZEN, C.. O trabalho com o Gênero Poético no processo de Formação de Leitores: possibilidades para o Ensino de Literatura. In: Anais [do] 40. Seminário de Literatura Infantil e J uvenil de Santa Catarina - SLIJ SC. Palhoça: Ed. Unisul, 2009. P. 530-537.

ZILBERMAN, R.. A leitura e o ensino da literatura. São Paulo: Ed. Contexto, 1988.

1Teses e Dissertações cujo resumo é aqui citado:

ASSUNÇÃO, R. B.. Prática e leitura de textos literários no Ensino Fundamental: Um diagnóstico. 1998. Dissertação (Mestrado em Educação) - UFMS.

CORDEIRO, E. A.. A literatura na 1a série do Ensino Médio: voz do aluno e do professor. 2002. Dissertação (Mestrado em Letras) - UFP.

DANTE, E. S.. Gostar de Ler: um estudo sobre alunos de Ensino Médio e sua relação com a leitura. 2006. Dissertação (Mestrado em Educação) - UNI MEP.

DINIZ, M. B.. A trama do texto no livro didático. 1994. Dissertação (Mestrado em Linguística e Língua Portuguesa) - UNESP.

FERREIRA, C. C.. Discussão sobre o ensino de leitura de textos literários: o desempenho dos candidatos na prova de Literaturas de Língua Portuguesa do vestibular UNICAMP. 1998. Dissertação (Mestrado em Linguística Aplicada) - UNICAMP.

JACONI, S. M. R.. A apresentação da literatura nos livros didáticos do Ensino Médio. 2006. Dissertação (Mestrado em Letras) - UPM.

OLIVEIRA, A. A.. A leitura e os textos literários infantis no contexto de escolas confessionais. 2001. Tese (Doutorado em Educação) - UNESP.

PADILHA, S. J.. Os gêneros poéticos em Livros didáticos de Língua Portuguesa do Ensino Fundamental: Uma abordagem enunciativo-discursiva. 2005. Tese (Doutorado em Linguística Aplicada e Estudos da Linguagem) - PUC/SP.

PINHEIRO, M. P.. Letramento literário na escola: um estudo das práticas de leitura literária na formação da comunidade de leitores. 2006. Teses (Doutorado em Educação) - UFMG.

SANTOS, A. N. C.. Arte, expressão, tradição, originalidade... Como ensinar literatura? 2005. Dissertação (Mestrado em Educação) - UCDB.

SILVA, R. J. A leitura literária nas 3a e 4a séries do Ensino Fundamental do município de Londrina. 2001. Dissertação (Mestrado em Letras) - UEL.

VERÍSSIMO, A. M.. O processo de formação do leitor de literatura no Ensino Médio: uma análise documental do tratamento metodológico dado aos textos literários, no livro didático. 2003. Dissertação (Mestrado em Educação) - UNOESTE.

VIOTTO, M. E. S.. A leitura, o ensino de literatura e o livro didático: uma questão a ser discutida. 2004. Dissertação (Mestrado em Letras) - UEM. 